\title{
The T-allele of the SMARCA4 gene has an apparent protective effect against high levels of total and LDL cholesterol
}

\author{
H.A.G.B. Queiroz ${ }^{1}$, F.S. Castro ${ }^{1,2}$, A.M.T.C. Silva ${ }^{1,2}$, C.M. Gomes ${ }^{1,2}$, \\ S.H.N. Costa ${ }^{1,2,3}$ and L.C. da Cunha ${ }^{3}$ \\ ${ }^{1}$ Faculdade de Ciências Médias, Farmacêuticas e Biomédias, Pontifícia \\ Universidade Católica de Goiás, Goiás, GO, Brasil \\ ${ }^{2}$ Faculdade da Polícia Militar do Estado de Goiás, Goiás, GO, Brasil \\ ${ }^{3}$ Faculdade de Farmácia, Universidade Federal de Goiás, Goiás, GO, Brasil \\ Corresponding author: S.H.N. Costa \\ E-mail: sergionascente17@gmail.com
}

Genet. Mol. Res. 19 (1): gmr18479

Received October 21, 2019

Accepted January 11, 2020

Published January 31, 2020

DOI http://dx.doi.org/10.4238/gmr18479

\begin{abstract}
The main polymorphisms linked to dyslipidemia include those of the SMARCA4 gene. We evaluated the association between lipidic profile and SMARCA4 gene polymorphism in 200 military police officers. Real time PCR was used to identify SMARCA4 gene polymorphisms. Among the subjects, 116 had dyslipidemia (case group), of which 94\% were males, and 84 presented no dyslipidemia (control group), of which $92 \%$ were males. For the SMARCA4 gene polymorphism, 66.4\% (77/116) presented the GG genotype, $31.0 \%$ (36/116), GT and $2.6 \%$ (3/116) TT. Individuals with GG, GT and TT genotypes had LDL cholesterol levels higher than $160 \mathrm{mg} / \mathrm{dL}$, respectively, at frequencies of 28.6 , 11.1 and $0 \%$, while total cholesterol higher than $190 \mathrm{mg} / \mathrm{dL}$, was at frequencies of $74.0,58.3$ and $33.3 \%$. Logistic regression analysis to determine the $\mathrm{p}$-values, considering the $\mathrm{T}$ allele as dominant, suggested that this allele has the ability to protect the individual from high cholesterol levels (OR, 0.488; 95\% CI $0.27-0.88 ; \mathrm{P}=0.0163$ ) and high LDL cholesterol levels (OR 0.277; 95\% CI 0.09 - 0.84; P = 0.0230). Absence of the $T$ allele was associated with increased susceptibility to dyslipidemia. Individuals who are homozygous or
\end{abstract}


heterozygous for the $\mathrm{T}$ allele are approximately two times more likely to have normal cholesterol levels, and about 3.5 times more likely to have normal LDL levels.

Key words: Dyslipidemia; Genetic polymorphism; LDL-cholesterol

\section{INTRODUCTION}

Police officers tend to have a predisposition for mental and physical illness. Military activity is not restricted to daily service only, since the police officer's position requires constant alertness, even during resting hours, since he/she can be summoned to work at any moment (Rodrigues et al., 2014). It is therefore a public profession with significant negative impacts on workers' health, such as life risk, work overload, inappropriate diet, constant alertness, rigid hierarchy and military discipline. These and other characteristics, inherent to police service, result in a high degree of exposure of the individual to various health problems (Rodrigues et al., 2014).

Among the various health problems of the police professional, dyslipidemia is prevalent. It is the alteration of the lipid levels in the blood, as a result of plasma lipoprotein metabolism disturbances, due to inadequate life habits (Rodrigues et al., 2014). These changes in the lipid profile may include elevation of total cholesterol, triglycerides (TG) and low-density lipoprotein cholesterol (LDL-c), as well as the decrease in high-density lipoprotein (HDL-c) cholesterol (ANVISA, 2011). Dyslipidemias can be grouped into hyperlipidemias (high level of lipoproteins) and hypolipidemias (low level of lipoprotein), and may, therefore, be associated with primary causes of genetic origin and secondary causes due to lifestyle and use of certain medications (SBC, 2017).

In addition, dyslipidemias may be classified as: isolated hypercholesterolemia (high LDL-c $\geq 160 \mathrm{mg} / \mathrm{dL}$ ); isolated hypertriglyceridemia (high TG alone $\geq 150 \mathrm{mg} / \mathrm{dL}$, reflecting increased VLDL, very low density lipoprotein, LDL, intermediate density lipoprotein, and chylomicrons); mixed hyperlipidemia (increased values of LDL-c $\geq 160$ $\mathrm{mg} / \mathrm{dL}$ and $\mathrm{TG} \geq 150 \mathrm{mg} / \mathrm{dL}$ ); and low HDL-c (reduction of HDL-c alone, men <40 $\mathrm{mg} / \mathrm{dL}$ and women $<50 \mathrm{mg} / \mathrm{dL})(\mathrm{SBC}, 2017)$.

The SMARCA4 gene (SWI/SNF Related, Matrix Associated, Actin Dependent Regulator of Chromatin, Subfamily A, Member 4) contains information for the synthesis of BRG1 (Brahma-Related Gene 1) protein, which makes up a subunit of many SWI protein complexes / SNF (SWItch / Non-Fermentable Sucrose). These complexes influence gene expression through chromatin remodeling (GuerreiroMartinez et al., 2018; Hoffmeister et al., 2019; Muthuswami et al., 2019).

The SMARCA4 gene has SNPs directly related to dyslipidemia. The gene is found on chromosome 19 (19p13.2), and the SNP rs1122608 (G/T) is related to the increase of LDL and the SNP rs2228671 (C/T), with high relation with the decrease of LDL (Zhou et al., 2015). We examined a possible association between the lipid profile and SMARCA4 gene polymorphism in members of the police force of the State of Goiás. 


\section{MATERIAL AND METHODS}

This was a case-control study, whose sample universe consisted of 200 active military police officers with similar ages. The individuals were selected through invitations from the Comprehensive Health Center of the Military Police (CHCMP). The inclusion criteria were: be over 18 years of age, and voluntarily participate in the study and the annual health assessment proposed by the CHCMP. About $10 \%$ of police officers were uncomfortable responding to the questionnaire and did not participate in the study. The volunteers who agreed to participate in the research signed the Informed Consent Form. This study was approved by the Ethics in Research Committee of the Goias Federal University (resolution $n^{\circ}$ 608.207).

Biological samples from the volunteers were collected $(4 \mathrm{~mL}$ of whole blood with EDTA) in the CHCMP and sent to the Laboratory of Human Cytogenetics and Molecular Genetics (LaGene) of the State Department of Health of Goiás and Research Nucleus Replicon of the Pontifical Catholic University of Goiás. From each biological sample, $2 \mathrm{~mL}$ aliquots were separated preserved in a freezer at $-20^{\circ} \mathrm{C}$ until use. Each DNA sample was isolated with the commercial Illustra Blood Genomic PrepMini Spin kit (GE Healthcare, UK), following the manufacturer's instructions. The extracted DNA was identified and stored at $-20^{\circ} \mathrm{C}$ and analyzed further in SMARCA4 SNP genotyping rs1122608 and rs2228671.

Genotyping of polymorphic sites was performed with the TaqMan Real Time PCR kit (SNP Genotyping Kit, Applied Biosystems, USA), which has primers that amplify the polymorphic sequence of interest, being C_27208850_10, Chr19, D19S865 FG, TaqMan® SNP Assays MTO, Human SM. By means of serum samples, the lipid profile was determined by enzymatic and direct methodology in automated equipment (A15, Biosystems), in the Goiás State Military Police Hospital Laboratory.

Data were analyzed to determine the absolute and relative percentages of genetic polymorphisms. For the inferential statistics the following tests were applied: Fisher's exact test and $G$, for categorical variables, and Student's t-test and MannWhitney test for continuous variables. Additionally, a logistic regression was used to compare the allele frequencies and genotypes of the cases and controls, with Odds Ratio (OR), 95\% confidence interval (95\% CI) and P-value. For all tests, a significance level of $5 \%$ was adopted. The analyses were performed using the BioEstat ${ }^{\circledR} 5.3$ software.

\section{RESULTS}

Among the 200 subjects, 116 presented dyslipidemia (case group), of which 94\% owererf males, and 84 did not present dyslipidemia (control group), with $92 \%$ males. In relation to the SMARCA4 gene polymorphism, $66.4 \%(77 / 116)$ presented the GG genotype, $31.0 \%$ (36/116), GT and 2.6\% (3/116), TT. Individuals with GG, GT and TT genotypes who had LDL cholesterol levels higher than $160 \mathrm{mg} / \mathrm{dL}$ were, respectively, 28.6, 11.1 and $0.0 \%$. For total cholesterol higher than $190 \mathrm{mg} / \mathrm{dL}$, frequencies were 74.0, 58.3 and 33.3, respectively (Table 1). 
Table 1. Frequencies of SMARCA4 gene polymorphism among Goias state police members, 2018.

\begin{tabular}{|c|c|c|c|c|c|c|c|c|c|c|c|c|}
\hline \multirow{3}{*}{ Variable } & \multicolumn{6}{|c|}{ Case (n=116) } & \multicolumn{6}{|c|}{ Control $(n=84)$} \\
\hline & \multicolumn{2}{|c|}{ GG (n=77) } & \multicolumn{2}{|c|}{ GT (n=36) } & \multicolumn{2}{|c|}{ TT $(n=3)$} & \multicolumn{2}{|c|}{ GG $(n=50)$} & \multicolumn{2}{|c|}{ GT (n=28) } & \multicolumn{2}{|c|}{ TT $(n=6)$} \\
\hline & $\mathbf{n}$ & $f(\%)$ & $\mathbf{n}$ & $\mathrm{f}(\%)$ & $\mathbf{n}$ & $f(\%)$ & $\mathrm{n}$ & $f(\%)$ & $\mathbf{n}$ & $\mathrm{f}(\%)$ & $\mathbf{n}$ & $f(\%)$ \\
\hline \multicolumn{13}{|l|}{ CT (mg/dL) } \\
\hline$<190$ & 20 & 26.0 & 15 & 41.7 & 2 & 66.7 & 34 & 68.0 & 22 & 78.6 & 5 & 83.3 \\
\hline$\geq 190$ & 57 & 74.0 & 21 & 58.3 & 1 & 33.3 & 16 & 32.0 & 6 & 21.4 & 1 & 16.7 \\
\hline \multicolumn{13}{|l|}{$\mathrm{T} \overline{\mathrm{G}}(\mathrm{mg} / \mathrm{dL})$} \\
\hline$<150$ & 14 & 18.2 & 7 & 19.4 & 0 & 0.0 & 50 & 100.0 & 28 & 100.0 & 6 & 100.0 \\
\hline$\geq 150$ & 63 & 81.8 & 29 & 80.6 & 3 & 100.0 & 0 & 0.0 & 0 & 0.0 & 0 & 0.0 \\
\hline \multicolumn{13}{|l|}{$\mathrm{HDL}(\mathrm{mg} / \mathrm{dL})$} \\
\hline$<40(\mathrm{M})<50(\mathrm{~F})$ & 61 & 79.2 & 31 & 86.1 & 2 & 66.7 & 22 & 44.0 & 14 & 50.0 & 3 & 50.0 \\
\hline$\geq 40(\mathrm{M}) \geq 50(\mathrm{~F})$ & 16 & 20.8 & 5 & 13.9 & 1 & 33.3 & 28 & 56.0 & 14 & 50.0 & 3 & 50.0 \\
\hline \multicolumn{13}{|l|}{ Non-HDL (mg/dL) } \\
\hline$<190$ & 45 & 58.4 & 22 & 61.1 & 3 & 100.0 & 50 & 100.0 & 28 & 100.0 & 6 & 100.0 \\
\hline$\geq 190$ & 32 & 41.6 & 14 & 38.9 & 0 & 0.0 & 0 & 0.0 & 0 & 0.0 & 0 & 0.0 \\
\hline \multicolumn{13}{|l|}{$\mathrm{L} \overline{\mathrm{D}} \mathrm{L}$} \\
\hline$<160$ & 55 & 71.4 & 32 & 88,9 & 3 & 100.0 & 50 & 100.0 & 28 & 100.0 & 6 & 100.0 \\
\hline$>160$ & 22 & 28.6 & 4 & 11.1 & 0 & 0.0 & 0 & 0.0 & 0 & 0.0 & 0 & 0.0 \\
\hline
\end{tabular}

Regarding the SMARCA4 gene polymorphism with the G allele, 97.4\% (113/116) were GG or GT, whereas $2.6 \%$ (3/116) were TT. Individuals with genotype GG or GT vs. TT had LDL cholesterol levels higher than $160 \mathrm{mg} / \mathrm{dL}$, respectively, in 23 and $0 \%$, and for total cholesterol greater than $190 \mathrm{mg} / \mathrm{dL}$, it was 69 and 33.3\% (Table 2).

Table 2. Polymorphism of SMARCA4 genes, with dominant $\mathrm{G}$ allele among Goias state police members, 2018.

\begin{tabular}{|c|c|c|c|c|c|c|c|c|c|c|c|c|}
\hline \multirow{3}{*}{ Variable } & \multicolumn{4}{|c|}{ Case } & \multicolumn{4}{|c|}{ Control } & \multirow{3}{*}{ OR } & \multirow{2}{*}{\multicolumn{2}{|c|}{ IC95\% }} & \multirow{3}{*}{ P-value } \\
\hline & \multicolumn{2}{|c|}{$\begin{array}{l}\text { GG+GT } \\
(n=113)\end{array}$} & \multicolumn{2}{|c|}{ TT $(\mathbf{n}=3)$} & \multicolumn{2}{|c|}{$\begin{array}{l}\text { GG+GT } \\
(n=78)\end{array}$} & \multicolumn{2}{|c|}{ TT(n=6) } & & & & \\
\hline & $\mathbf{n}$ & $\mathbf{f}(\%)$ & $\mathbf{n}$ & $f(\%)$ & $\mathbf{n}$ & $\mathbf{f}(\%)$ & $\mathbf{n}$ & $\mathbf{f}(\%)$ & & low & high & \\
\hline \multicolumn{13}{|l|}{ CT (mg/dL) } \\
\hline$<190$ & 35 & 31.0 & 2 & 66.7 & 56 & 71.8 & 5 & 83.3 & & & & \\
\hline$\geq 190$ & 78 & 69.0 & 1 & 33.3 & 22 & 28.2 & 1 & 16,7 & 3.846 & 0.78 & 18.99 & 0.0983 \\
\hline \multicolumn{13}{|l|}{$\overline{\mathrm{T}} \mathrm{G}(\mathrm{mg} / \mathrm{dL})$} \\
\hline$<150$ & 21 & 18.6 & 0 & 0.0 & 78 & 100.0 & 6 & 100.0 & & & & \\
\hline$\geq 150$ & 92 & 81.4 & 3 & 100.0 & 0 & 0.0 & 0 & 0.0 & 1.859 & 0.45 & 7.65 & 0.3905 \\
\hline \multicolumn{13}{|l|}{ HDL $(\mathrm{mg} / \mathrm{dL}))$} \\
\hline$<40(\mathrm{M})<50(\mathrm{~F})$ & 92 & 81.4 & 2 & 66.7 & 36 & 46.2 & 3 & 50.0 & & & & \\
\hline$\geq 40(\mathrm{M}) \geq 50(\mathrm{~F})$ & 21 & 18.6 & 1 & 33.3 & 42 & 53.8 & 3 & 50.0 & 1.625 & 0.42 & 6.26 & 0.4803 \\
\hline \multicolumn{13}{|c|}{ Non-HDL (mg/dL) } \\
\hline$<190$ & 67 & 59.3 & 3 & 100.0 & 78 & 100.0 & 6 & 100.0 & & & & \\
\hline$\geq 190$ & 46 & 40.7 & 0 & 0.0 & 0 & 0.0 & 0 & 0.0 & 4552.192 & 0.00 & $\infty$ & 0.7280 \\
\hline \multicolumn{13}{|l|}{ LDL } \\
\hline$<160$ & 87 & 77.0 & 3 & 100.0 & 78 & 100.0 & 6 & 100.0 & & & & \\
\hline$\geq 160$ & 26 & 23.0 & 0 & 0.0 & 0 & 0.0 & 0 & 0.0 & 4000.411 & 0.00 & $\infty$ & 0.7968 \\
\hline
\end{tabular}


Regarding the SMARCA4 polymorphism with the T allele, $66.4 \%$ (77/116) were GG, while 33.6\% (39/116) were GT or TT. Individuals with GG and GT or TT genotypes had LDL cholesterol levels higher than $160 \mathrm{mg} / \mathrm{dL}$, respectively, in 28.6 and $10.3 \%$, and total cholesterol greater than $190 \mathrm{mg} / \mathrm{dL}$, occurred in 74 and $56.4 \%$ (Table 3).

Table 3. Polymorphism of SMARCA4 genes, with dominant $\mathrm{T}$ allele among Goias state police members, 2018.

\begin{tabular}{|c|c|c|c|c|c|c|c|c|c|c|c|c|}
\hline \multirow{3}{*}{ Variable } & \multicolumn{4}{|c|}{ Case } & \multicolumn{4}{|c|}{ Control } & \multirow{3}{*}{ OR } & \multirow{2}{*}{\multicolumn{2}{|c|}{ CI95\% }} & \multirow{3}{*}{ P-value } \\
\hline & \multicolumn{2}{|c|}{$\begin{array}{l}\mathbf{G G} \\
(\mathbf{n}=77)\end{array}$} & \multicolumn{2}{|c|}{$\begin{array}{l}\text { GT+TT } \\
(\mathbf{n}=39)\end{array}$} & \multicolumn{2}{|c|}{ GG $(n=50)$} & \multicolumn{2}{|c|}{$\mathbf{G T}+\mathbf{T T}(\mathrm{n}=34)$} & & & & \\
\hline & n & $\mathbf{f}(\%)$ & $\mathbf{n}$ & $\mathbf{f}(\%)$ & $\mathbf{n}$ & $\mathbf{f}(\%)$ & $\mathbf{n}$ & $\mathbf{f}(\%)$ & & low & high & \\
\hline \multicolumn{13}{|l|}{$\mathrm{TC}(\mathrm{mg} / \mathrm{dL})$} \\
\hline$<190$ & 20 & 26.0 & 17 & 3.6 & 34 & 68.0 & 27 & 79.4 & & & & \\
\hline$\geq 190$ & 57 & 74.0 & 22 & 6.4 & 16 & 32.0 & 7 & 20.6 & 0.488 & 0.27 & 0.88 & $0.0163 *$ \\
\hline \multicolumn{13}{|l|}{$\overline{\mathrm{T}} \mathrm{G}(\mathrm{mg} / \mathrm{dL})$} \\
\hline$<150$ & 14 & 18.2 & 7 & 17.9 & 50 & 100.0 & 34 & 100.0 & & & & \\
\hline$\geq 150$ & 63 & 81.8 & 32 & 82.1 & 0 & 0.0 & 0 & 0.0 & 0.793 & 0.44 & 1.41 & 0.4317 \\
\hline \multicolumn{13}{|l|}{ HDL (mg/dL) } \\
\hline$<40(\mathrm{M})<50(\mathrm{~F})$ & 61 & 79.2 & 33 & 84.6 & 22 & 44.0 & 17 & 50.0 & & & & \\
\hline$\geq 40(\mathrm{M}) \geq 50(\mathrm{~F})$ & 16 & 20.8 & 6 & 15.4 & 28 & 56.0 & 17 & 50.0 & 1.152 & 0.62 & 2.13 & 0.6508 \\
\hline \multicolumn{13}{|c|}{ Non-HDL (mg/dL) } \\
\hline$<190$ & 45 & 58.4 & 25 & 64.1 & 50 & 100.0 & 34 & 100.0 & & & & \\
\hline$\geq 190$ & 32 & 41.6 & 14 & 35.9 & 0 & 0.0 & 0 & 0.0 & 0.704 & 0.35 & 1.43 & 0.3315 \\
\hline \multicolumn{13}{|l|}{ LDL } \\
\hline$<160$ & 55 & 71.4 & 35 & 89.7 & 50 & 100.0 & 34 & 100.0 & & & & \\
\hline$\geq 160$ & 22 & 28.6 & 4 & 10.3 & 0 & 0.0 & 0 & 0.0 & 0.277 & 0.09 & 0.84 & $0.0230 *$ \\
\hline
\end{tabular}

Logistic regression analysis, considering the $\mathrm{T}$ allele as dominant, showed that this allele has the ability to protect the individual from increased total cholesterol $(\mathrm{P}=0.0163)$ and LDL cholesterol $(P=0.0230)$. However, such an outcome does not imply that the $G$ allele is the cause of the disease, but that the absence of the $\mathrm{T}$ allele may increase individual susceptibility to the development of increased cholesterol levels. Thus, individuals who have the $\mathrm{T}$ allele in both homozygous and heterozygous forms are approximately twice as likely to have normal cholesterol as individuals who do not have this allele. In addition, one who has the $\mathrm{T}$ allele is about 3.5 times more likely to have normal LDL. LDL is the main cofactor for atherosclerotic disease.

\section{DISCUSSION}

The condition of police officers, due to high risk work, deserves a more careful investigation by the health teams. Among the various problems faced by this profession, dyslipidemia, a disorder in lipid metabolism, has been highlighted (Prado et al., 2012). This alteration can be classified as hyperlipidemias and hypolipidemias, that is, high and low levels of lipoproteins, respectively. Both hyper and hypolipidemia may be associated with primary causes, that is, of genetic origin, or secondary causes, related to lifestyle, use of specific medications and others. The prevalence of dyspidemias in this group increases with age similar to that of the rest of the Brazilian population (Miller, 1999; SBC, 2017). 
Primary dyslipidemia may be related to the SMARCA4 gene, which is present in all individuals. The gene is found on chromosome 19, and rs1122608 (G/T) SNP is related to the increase of LDL and the SNP rs2228671 (C/T), with a high relation with the decrease of LDL (Zhou et al., 2015)]. Humans have two alleles of the SMARCA4, $\mathrm{T}$ and G gene, and may be heterozygotes (GT) or homozygotes (GG or TT). In this study, the dominant allele $\mathrm{T}$ has been shown to provide protection against increased blood levels of high cholesterol as well as its main lipoprotein carrier, LDL, which is associated with the development of atherosclerosis. Thus, in addition to the genetic factor, environmental factors, such as the lifestyle and diet of the individuals evaluated, should be considered (Rodrigues et al., 2014).

A study in Tianjin, China, investigated the psychic suffering of 3,300 police officers initially without dyslipidemia (2,567 with dyslipidemia), 60.5\% ( $\mathrm{n}=1829)$ developed dyslipidemia 2.6 years later (Chen et al., 2015), showing that in addition to genetic factors, the lifestyle can lead these professionals to the development of the disease. Other studies claim that one of the leading causes of death in the world is coronary disease, resulting in 700,000 deaths in China and 502,000 deaths in the United States (Lopez et al., 2006; Zhang et al., 2008). Coronary disease is complex and multifactorial, that is, it involves several genes (genetic factor) and an important contribution of the lifestyle (environmental factor). In this context, there are risk factors that increase the probability of the disease occurring, such as age, sex and lipid profile (Bhasin et al., 2011).

The SMARCA4 gene encodes an ATP-dependent BRG1 helicase and belongs to the SWI / SNF complex (Moes-Sosnowska et al., 2015). According to research, this gene is one of the most mutated subunits and is therefore involved in mechanisms by which the alteration increases the probability of the onset of the disease (Wilson et al., 2014). Previous studies have found variants affected in lipid parameters and dyslipidemia, such as polymorphisms: rs11879293, rs12232780, rs2072382 and rs1529729 (Liu et al., 2011; Zhong et al., 2014). The study of the Chinese population showed two susceptibility SNPs are in the SMARCA4 gene that were potentially associated with a reduced risk of CHD found that significant differences Serum LDL-C and HDL-C (Guo et al., 2017).

\section{CONCLUSIONS}

The $\mathrm{T}$ allele acts as dominant, suggesting it might be protective for the development of high cholesterol. However, it does not mean that the $G$ allele causes the disease, but that the absence of the $\mathrm{T}$ allele may increase susceptibility to the development of high cholesterol levels. Therefore, individuals who have the T allele in both homozygous and heterozygous forms are approximately twice as likely to have normal cholesterol. In addition, the T allele decreases about 3.5 times the individual's chances of having LDL change. It is worth mentioning that LDL is one of the main factors related to atherosclerosis. 


\section{ACKNOWLEDGMENTS}

We thank the Foundation for Research Support of the State of Góias (FAPEG) for funding for and execution of the present study.

\section{CONFLICTS OF INTEREST}

The authors declare no conflict of interest.

\section{REFERENCES}

ANVISA (2011). Dislipidemia. Saúde e Economia 3(6): 1-4.

Bhasin SK, Dwivedi S, Dehghani A and Sharma R (2011) Conventional risk factors among newly diagnosed coronary heart disease patients in Delhi. World J. Cardiol. 3(6): 201-6.

Chen X, Leng L, Yu H, Yang X, et al. (2015). Psychological Distress and Dyslipidemia in Chinese Police Officers: A 4Year Follow-Up Study in Tianjin, China. J. Occup. Environ. Med. 57(4): 400-5.

Guerreiro-Martinez JÁ and Reyes JC (2018). High expression of SMARCA4 or SMARCA2 is frequently associated with an opposite prognosis in cancer. Sci. Rep. 8(1): 2043.

Guo X, Wang X, Wang Y, Zhang Y, et al. (2017) Variants in the SMARCA4 gene was associated with coronary heart disease susceptibility in Chinese Han population. Oncotarget. 8(5): 7350-7356.

Hoffmeister H, Fuchs A, Strobl L, Sprenger F, et al. (2019). Elucidation of the functional role of the Q- and I-motif in the human chromatin remodeling enzyme BRG1. J. Biol. Chem. 294: 3294-3310.

Liu Y, Zhou D, Zhang Z, Song Y, et al. (2011). Effects of genetic variants on lipid parameters and dyslipidemia in a Chinese population. J. Lipid Res. 52(2): 354-60.

Lopez AD, Mathers CD, Ezzati M, Jamison DT, et al. (2006). Global and regional burden of disease and risk factors, 2001: systematic analysis of population health data. Lancet. 367(9524): 1747-57.

Miller GJ (1999). Lipoproteins and the haemostatic system in atherothrombotic disorders. Best Pract. Res. Clin. Haematol. 12(3): 555-75.

Moes-Sosnowska J, Szafron L, Nowakowska D, Dansonka-Mieszkowska A, et al. (2015). Germline SMARCA4 mutations in patients with ovarian small cell carcinoma of hypercalcemic type. Orphanet J. Rare Dis. 10: 32.

Muthuswami R, Bailey L, Rakesh R, Imbalzano AN, et al. (2019). BRG1 is a prognostic indicator and a potential therapeutic target for prostate cancer. J. Cell Physiol. 1-12.

Prado ES and Dantas EHM (2002) Efeitos dos exercícios físicos aeróbio e de força nas lipoproteínas HDL, LDL e lipoproteína(a). Arq. Bras. Cardiol. 79(4): 429-33.

Rodrigues PF and Lourinho LA (2014). The Illness Psychological Thriller of Military Ceará. Rev. Trab. e Soc. 22: 5877.

SBC - Sociedade Brasileira de Cardiologia (2017). Atualização da diretriz brasileira de dislipidemias e prevenção da aterosclerose. Arq. Bras. Cardiol. 109(1): 76.

Wilson BG, Helming KC, Wang X, Kim Y, et al. (2014). Residual complexes containing SMARCA2 (BRM) underlie the oncogenic drive of SMARCA4 (BRG1) mutation. Mol. Cell Biol. 34(6): 1136-44.

Zhang X-H, Lu ZL and Liu L (2008). Coronary heart disease in China. Heart. 94(9): 1126-31.

Zhong R, Liu L, Tian Y, Wang Y, et al. (2014). Genetic variant in SWI/SNF complexes influences hepatocellular carcinoma risk: a new clue for the contribution of chromatin remodeling in carcinogenesis. Sci. Rep. 21: 4-4147.

Zhou YJ, Hong SC, Yang Q, Yin RX, et al. (2015). Association of variants in CELSR2-PSRC1-SORT1 with risk of serum lipid traits, coronary artery disease and ischemic stroke. Int. J. Clin. Exp. Pathol. 8(8): 9543-51 